\title{
I 38 Relationship between coronary calcification and endothelium dependent coronary vaso-reactivity in asymptomatic diabetic patients without overt coronary artery disease

\author{
Olakunle Akinboboye ${ }^{1}$, Yi Wang ${ }^{2}$, Michael Jerosch-Herold ${ }^{2}$, Karen Ngai ${ }^{1}, \mathrm{M}$ \\ Rizwan Khalid*1, Rafael Dim³ ${ }^{3}$ Kathy McGrath² and Marguerite Roth ${ }^{2}$
}

\author{
Address: ${ }^{1}$ New York Hospital Medical Center Queens, Flushing, NY, USA, ${ }^{2}$ Saint Francis Hospital, Roslyn, NY, USA and ${ }^{3}$ SUNY Downstate, \\ Brooklyn, NY, USA \\ * Corresponding author
}

from I I th Annual SCMR Scientific Sessions

Los Angeles, CA, USA. I-3 February 2008

Published: 22 October 2008

Journal of Cardiovascular Magnetic Resonance 2008, I0(SuppI I):A39 doi:10.1 I86/I532-429X-10-SI-A39

This abstract is available from: http://jcmr-online.com/content/I0/SI/A39

(c) 2008 Akinboboye et al; licensee BioMed Central Ltd.

\section{Introduction}

The relationship between coronary calcification and endothelium dependent coronary vaso-reactivity in patients with diabetes mellitus is poorly understood.

\section{Purpose}

We hypothesize that endothelium dependent coronary vaso-reactivity; in asymptomatic diabetic patients without myocardial ischemia is impaired in vascular territories with coronary calcification.

\section{Methods}

We studied 23 (mean age $63 \pm 10,19 \mathrm{M}, 4 \mathrm{~F}$ ) patients with type II DM, without history, symptom or ECG evidence of $\mathrm{CAD}$. The subjects underwent 1 -day rest-stress adenosine nuclear stress test, assessment of coronary calcification by EBCT and absolute measurement of myocardial blood flow at rest (MBF-R), and following cold-water hand immersion for 1 minute (MBF-C). All imaging studies were performed within 24 hours. Flow measurements by CMRI was performed using saturation recovery TurboFLASH imaging sequence: TR/TE/TI/FA $=2.9 \mathrm{~ms} / 1.3 \mathrm{~ms} /$ $90 \mathrm{~ms} / 6^{\circ}$, data matrix $128 \times 70$, and usual voxel spatial resolution $3.5 \times 1.9 \times 8 \mathrm{~mm}^{3}$. Contrast dose was 0.05 $\mathrm{mmol} / \mathrm{kg}$ (Omniscan, Amersham). All scans were processed in a blinded fashion. Using Medis software (Leiden University, the Netherlands), basal, mid-cavity and apical slices were divided into 6 equal transmural sectors. After correction for coil sensitivity variations, model independent deconvolution of myocardial signal intensity curves in the sectors, with blood pool signal intensity curves was performed. MBF-R and MBF-C in $\mathrm{mls} / \mathrm{g} / \mathrm{min}$ were determined. Endothelium dependent perfusion reserve (MPR) in these sectors were calculated as the ratios of MBF-C to MBF-R in each sector. The sectors wre subsequently grouped based on standard coronary vascular distribution.

Difference between means of two groups of patients was calculated using Student's t-test while One-way ANOVA model was utilized to compare means amongst three groups. P-value of $<0.05$ was considered significant

The vascular sectors were stratified into 3 groups (A, B, C) based on the Agatston calcium score of their respective coronary arteries from $0,1-100,101-400$ respectively.

\section{Results}

MPR in groups A B and C were $1.22 \pm 0.4,1.11 \pm 0.3$ and $1.01 \pm 0.24$ respectively ( $\mathrm{p}=0.03$ for A vs (B and C combined)) (See Figure 1). We also compared mean differences in vaso-reactivity for Groups A, B, and C separately to assess whether a graded relationship exists between vaso-reactivity and the extent of calcification. This model was not significant $(\mathrm{p}=0.19)$. 


\section{MPR vs Calcium Score}

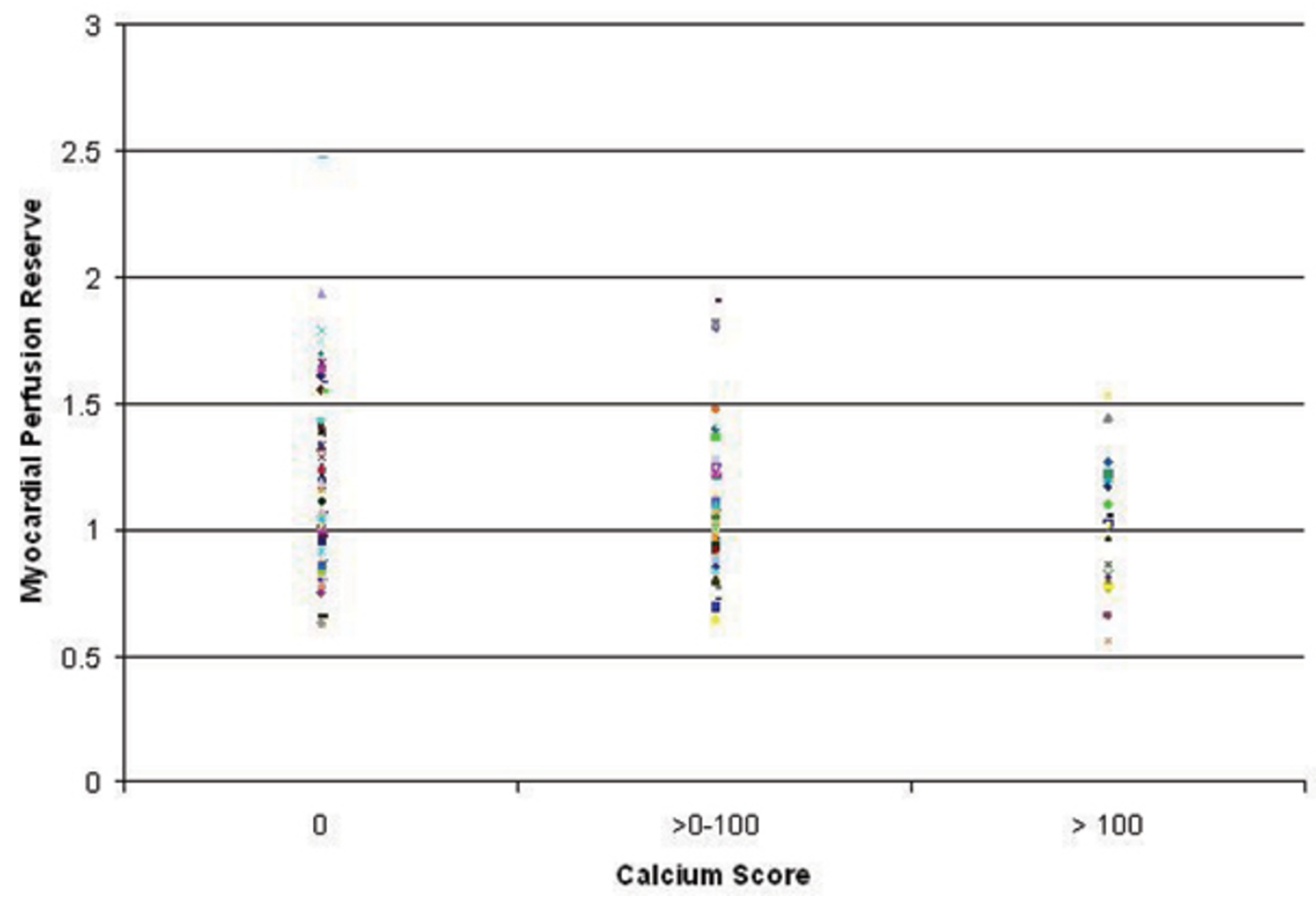

Figure I

Endothelium-dependent perfusion reserve(MPR), as a marker for coronary vaso-reactivity, is impaired in coronary arteries with any amount of calcification. MPR was calculated by measuring myocardial blood flow during rest and during immersion for I minute in cold-water by Cardiac MRI.

\section{Conclusion}

Endothelium-dependent vaso-reactivity is impaired in vascular territories with any amount of calcification compared with vascular territories without calcification. We do not have evidence to support a quantitative relationship between endothelium dependent coronary vasoreactivity and the extent of calcification.

Publish with Biomed Central and every scientist can read your work free of charge

"BioMed Central will be the most significant development for disseminating the results of biomedical research in our lifetime." Sir Paul Nurse, Cancer Research UK

Your research papers will be:

- available free of charge to the entire biomedical community

- peer reviewed and published immediately upon acceptance

- cited in PubMed and archived on PubMed Central

- yours - you keep the copyright 